\title{
Removal of E. coli from Water using Surface Modified Activated Carbon Filter Media and its Performance over an Extended Use
}

\author{
'Research Institute of Pharmaceutical Sciences and College of Pharmacy, \\ Seoul National University, Seoul 151-742, South Korea \\ ${ }^{\S}$ School of Materials Science \& Engineering, \\ Seoul National University, Seoul 151-742, South Korea
}

* Corresponding author: Joon Myong Song,

Tel.: 82-2-880-7841, Fax: 82-2-871-2238, E-mail address: jmsong@ snu.ac.kr

${ }^{\ddagger}$ Present address: Centre for Nanomaterials, International Advanced Research Institute for Powder Metallurgy and New Materials (ARCI), Balapur PO, Andhra Pradesh, Hyderabad 500 005, India

\section{ENVIRONMENTAL SCIENCE AND TECHNOLOGY}

June 16, 2006 


\section{Summary of the number of pages and contents}

Number of Pages: 12

Methods of modification of filter media

Crystallite size analysis of $\mathrm{AgBr}$ by integral breadth method

Experimental details for bacterial removal kinetics

Figure S1. Schematic diagram of the prototype and column

Figure S2. ${ }^{27} \mathrm{Al}$ MAS NMR of AC treated with AHC

Figure S3: XRD patterns of $\mathrm{AC}$ and $\mathrm{Ag}-\mathrm{AC}$

Table S1. Metal leach out from filter media

Table S2. Performance of modified filter media to inhibit growth of E. coli on the used media 


\section{Methods of modification of filter media:}

By aluminum hydroxychloride: In a typical experiment a $50 \%(w / v)$ aqueous slurry of granular filter media (AC or DE) was gradually treated with a solution of aluminum hydroxychloride with continuous stirring using an overhead stirrer at a speed of $120 \mathrm{rpm}$. The $\mathrm{pH}$ of the filer media slurry was adjusted to 6.0 to 6.5 by using dilute hydrochloric acid $(0.01 \mathrm{~N})$ or sodium hydroxide solution $(0.01 \mathrm{~N})$ as applicable, prior to the addition of aluminum hydroxychloride solution. After an hour granular material was filtered out, washed thoroughly with distilled water (at least 10 times of the initial volume), and finally dried overnight at $40^{\circ} \mathrm{C}$.

By in situ precipitation of zinc hydroxide: A zinc sulfate solution (0.3 M, $100 \mathrm{ml})$ was slowly added to an aqueous slurry of granular filter media $(100 \mathrm{~g}$ in $100 \mathrm{ml})$ with continuous stirring using an overhead stirrer at a speed of $100 \mathrm{rpm}$. The $\mathrm{pH}$ of the slurry was maintained in between 6.0 to 7.0 by adding sulfuric acid $(0.01 \mathrm{~N})$ or sodium hydroxide solution $(0.01 \mathrm{~N})$. After an hour, granular media was filtered out, washed thoroughly with at least $3 \mathrm{~L}$ of distilled water, and finally dried overnight at $60^{\circ} \mathrm{C}$.

In situ precipitation of silver halide on activated carbon: Activated carbon (100g) was soaked to saturation in a solution of silver nitrate containing $\sim 0.2 \%(\mathrm{w} / \mathrm{w})$ of $\mathrm{Ag}$ in dark, and then a solution of potassium bromide (slight excess than the equivalent amount of $\mathrm{AgNO}_{3}$ ) was added drop wise with continuous stirring. The mixture was allowed to stand for $1 \mathrm{hr}$ with occasional stirring. The media was then filtered out, rinsed with 5 - 6 liter of distilled water and dried at $60^{\circ} \mathrm{C}$. Modification of silver halide coated activated carbon by aluminum hydroxychloride: Fifty grams of silver halide modified activated carbon was treated with $100 \mathrm{ml}$ of $10 \%(\mathrm{w} / \mathrm{v})$ aqueous solution of aluminum hydroxychloride using a process as described above.

Modification of activated carbon treated with aluminum hydroxychloride by DADMAC: A batch of $100 \mathrm{~g}$ of dried carbon already treated with aluminum hydroxychloride was slurried with $200 \mathrm{ml}$ of water. $100 \mathrm{ml}$ of $5 \%(\mathrm{w} / \mathrm{v})$ solution of DADMAC was added to the slurry with 
continuous stirring. The mixture was stirred for few hours. Then the treated carbon was filtered out, washed with at least two liters of distilled water and dried overnight at $40^{\circ} \mathrm{C}$.

Modification of aluminum hydroxychloride treated activated carbon with TCC: About $100 \mathrm{~g}$ of the dried carbon already treated with aluminum hydroxychloride was slurried with $200 \mathrm{ml}$ of water. $100 \mathrm{ml}$ of $5 \%(\mathrm{w} / \mathrm{v})$ alcoholic solution of triclocarban (TCC) was then added to slurry with stirring. The mixture was stirred for at least $1 \mathrm{~h}$, and then the treated carbon was filtered out, washed with at least two liters of distilled water and dried overnight at $40^{\circ} \mathrm{C}$. 


\section{Crystallite size analysis of AgBr by integral breadth method:}

The method involves deconvolution of the XRD peak profile into Cauchy and Gaussian fractions, where the cauchy $\left(\beta_{\mathrm{c}} / \beta\right)$ and gaussian fraction $\left(\beta_{\mathrm{g}} / \beta\right)$ of the integral breadth $(\beta)$ are given by the empirical expressions:

$$
\begin{aligned}
& \frac{\beta_{c}}{\beta}=2.027-0.4803 \phi-1.7756 \phi^{2} \\
& \frac{\beta_{g}}{\beta}=0.642+1.4187\left(\phi-\frac{2}{\pi}\right)^{1 / 2}-2.2043 \phi+1.8706 \phi^{2}
\end{aligned}
$$

' $\phi$ ' is the shape factor for the voigt function and is defined as the ratio of full width at half maxima (FWHM) and the integral breadth $(\beta)$. Cauchy and Gaussian functions are the limiting cases for the voigt function so that ' $\phi$ ' varies in the range of:

$$
\frac{2}{\pi} \leq \phi \leq 2 \sqrt{\frac{\ln 2}{\pi}}
$$

XRD profile from pure $99.999 \%$ Si standard was obtained for instrumental broadening and zero shift corrections. The instrumental broadening constituents, $\beta$ (i) for the cauchy and gaussian fractions are related to the integral breadth of the observed broadening, $\beta(h)$, and the real broadening $\beta(f)$ following the expressions:

$\beta_{c}(f)=\beta_{c}(h)-\beta_{c}(i)$

$\beta_{\mathrm{g}}(\mathrm{f})=\left\{\left(\beta_{\mathrm{g}}(\mathrm{h})\right)^{2}-\left(\beta_{\mathrm{g}}(\mathrm{i})\right)^{2}\right\}^{1 / 2}$

The method considers that the crystallite size of the sample (D) contributes to the Cauchy component while the lattice strain $(\varepsilon)$ accounts for the Gaussian fraction of the XRD peak and is given by the relation:

$$
D=\frac{\lambda}{\beta_{c}(f) \cos \theta}
$$


$\varepsilon=\frac{\beta_{g}(f)}{4 \tan \theta}$ 


\section{Experimental details for bacterial removal kinetics:}

Bacterial removal kinetics of four differently treated activated carbon materials was determined under batch conditions at $25^{\circ} \mathrm{C}$. The $\mathrm{pH}$ was adjusted to 7.0 with weak $\mathrm{KOH}$ solution (final electrolyte concentration $1 \times 10^{-3} \mathrm{M}$ ). Initial E.coli solution of $10^{7} \mathrm{CFU} / \mathrm{mL}$ was prepared in $\mathrm{pH}$ adjusted distilled water. Batch experiment was performed in 50-mL sterilized polypropylene conical tubes each containing $10 \mathrm{~mL}$ volume of E.coli sample and $2 \mathrm{~g}$ of different filter materials. The tubes were placed horizontally in a shaking incubator (NB $250 \mathrm{~V}$, N-Biotek, Korea) and were agitated at a speed of $100 \mathrm{rpm}$. Bacterial removal was determined by microbiologically analyzing the supernatant sampled at various times using standard plate counting method. Batch experiment performed under the same condition in absence of filter media was taken as control. 


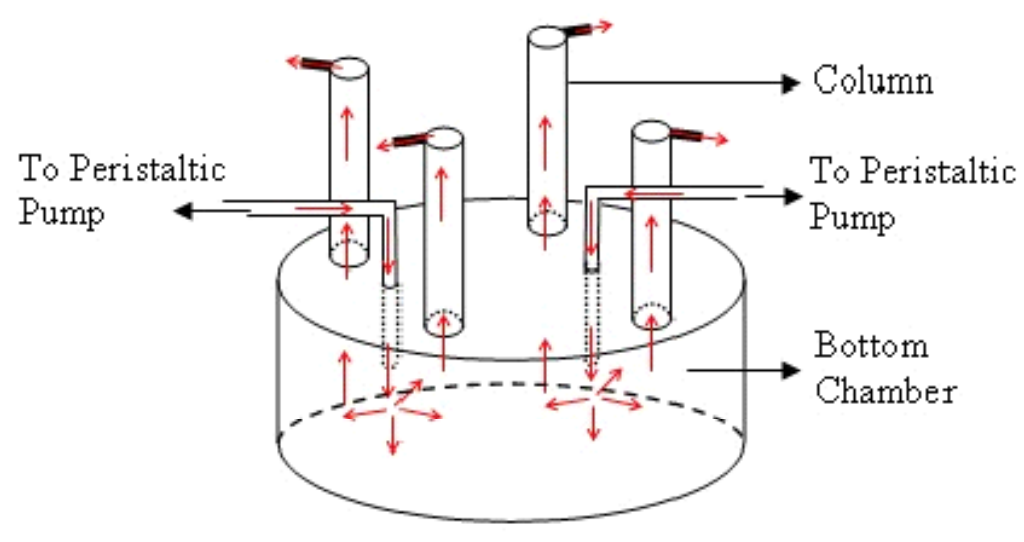

a

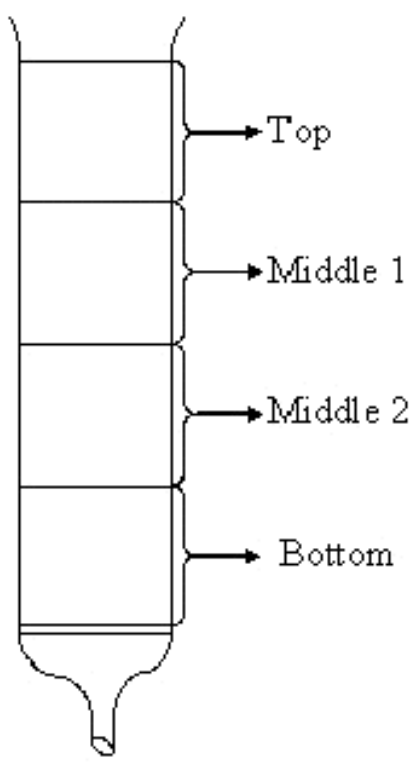

b

Figure S1. a) Schematic diagram of the experimental arrangement for extended life time test of filter media. Column dimension: $25 \mathrm{~mm}$ in diameter and $100 \mathrm{~mm}$ long; Bottom chamber dimension: $200 \mathrm{~mm}$ ID and $100 \mathrm{~mm}$ height. Red arrows indicate the flow path of water. Contaminated water was passed through the column vertically upward.

b) Schematic diagram of column used for short term evaluation of filter media. Contaminated water was passed through the column vertically down ward (top to bottom). The used materials were divided in to four layers of almost equal length (from top- to-bottom) and were removed from a column to study bacterial growth on filter media. 


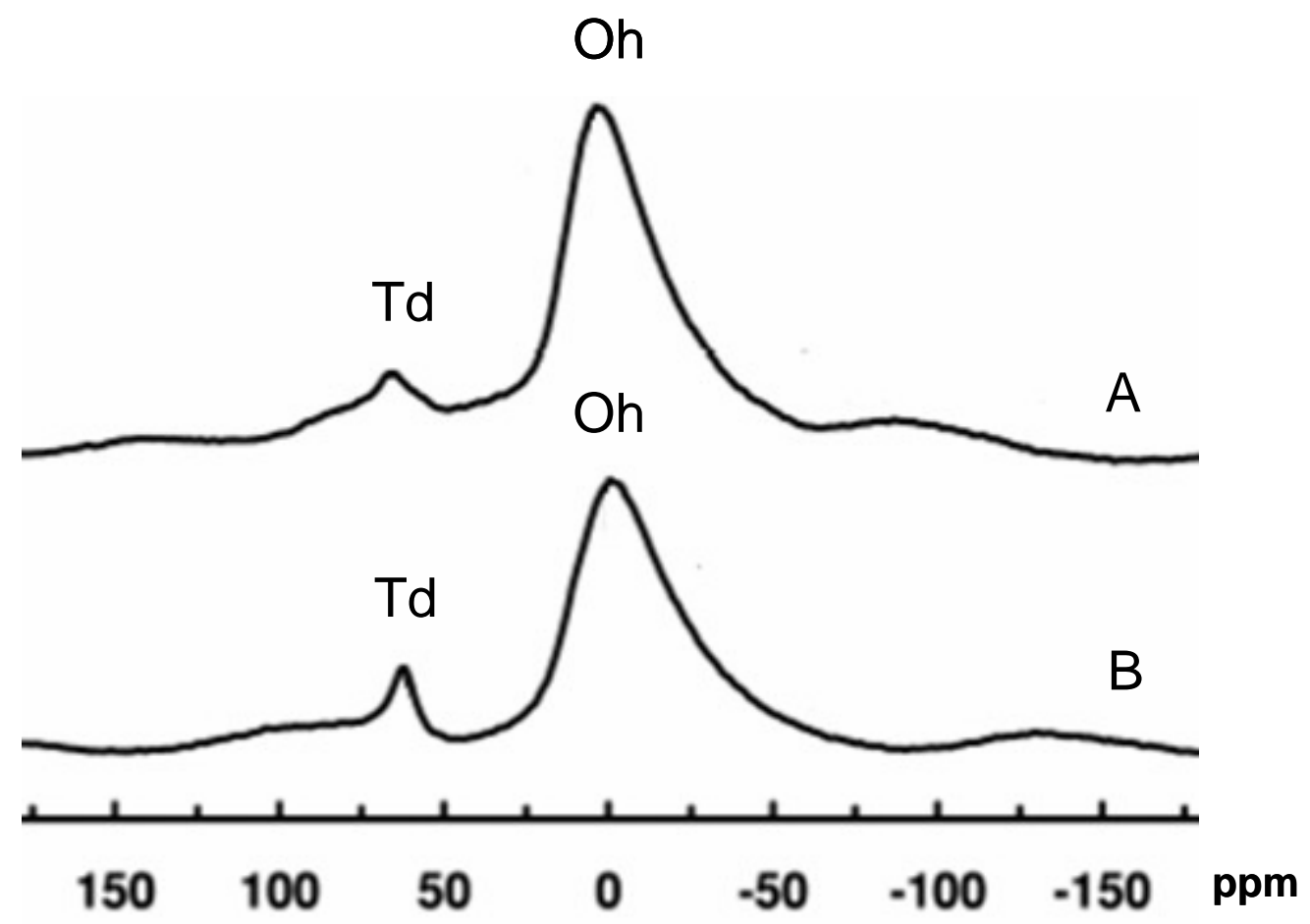

Figure S2. ${ }^{27} \mathrm{Al}$ MAS NMR of AC treated with AHC, A) 7.5\% AHC-AC (60x200mesh), B) 10\% AHC-AC $\left(60 \times 200\right.$ mesh). Satellites are barely visible. The characteristic ${ }^{27} \mathrm{Al}$ NMR spectrum of " $\mathrm{Al}_{13}$ " displays the presence of two environments of aluminium, the signal at $\sim 0-10 \mathrm{ppm}$ could be from shell-structured octahedral $(\mathrm{Oh}) \mathrm{Al}$ and that at $\sim 63-65 \mathrm{ppm}$ could be assigned to the tetrahedral (Td) Al. 


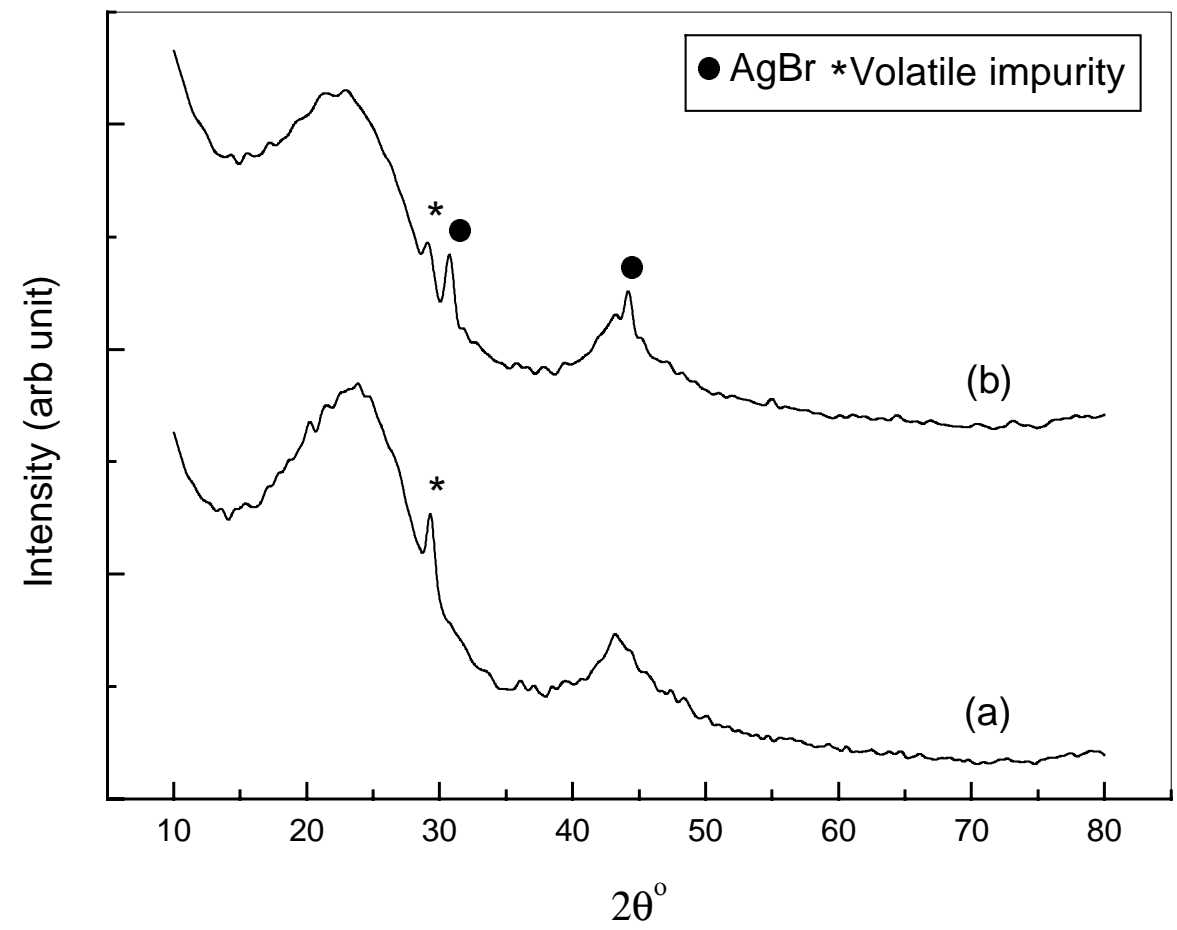

Figure S3. XRD profiles of (a) blank amorphous activated carbon and (b) activated carbon modified by in situ precipitation of silver bromide (Ag AC). The XRD patterns reveal the presence of only $\mathrm{AgBr}$ in (b). Some amount of volatile impurities in the carbon is also evident from the figure, which disappears on being treated at higher temperature of $230^{\circ} \mathrm{C}$ (not shown in the figure). 
Table S1. Metal leach out from filter media

\begin{tabular}{|c|c|c|c|c|c|c|}
\hline \multirow[t]{2}{*}{ Filter Media } & \multicolumn{3}{|c|}{ Metal Leach after $4 \mathrm{~L}$ (in ppm) } & \multicolumn{3}{|c|}{ Metal Leach after $9 \mathrm{~L}$ (in ppm) } \\
\hline & $\mathrm{Al}$ & $\mathrm{Zn}$ & $\mathrm{Ag}$ & $\mathrm{Al}$ & $\mathrm{Zn}$ & $\mathrm{Ag}$ \\
\hline $\mathrm{AC}$ & 0.005 & ND & ND & 0.002 & ND & ND \\
\hline $\begin{array}{l}10 \% \text { AHC- } \\
\text { DADMAC-AC }\end{array}$ & 0.012 & NA & NA & 0.004 & & NA \\
\hline $10 \%$ AHC-TCC-AC & 0.010 & NA & NA & 0.006 & NA & NA \\
\hline $10 \%$ AHC-Ag-AC & 0.049 & NA & 0.03 & 0.010 & NA & ND \\
\hline $\mathrm{Ag}-\mathrm{AC}$ & 0.007 & NA & 0.04 & NA & $\mathrm{NA}$ & ND \\
\hline $\begin{array}{l}\mathrm{Ag}-\mathrm{AC} \quad(60 \times 200) \\
(\text { Commercial })\end{array}$ & 0.009 & NA & 0.942 & NA & & 0.121 \\
\hline $\begin{array}{l}\mathrm{Ag}-\mathrm{AC} \quad(30 \times 60) \\
(\text { Commercial })\end{array}$ & 0.002 & NA & 0.067 & NA & NA & 0.037 \\
\hline $\mathrm{DE}$ & ND & ND & ND & ND & ND & ND \\
\hline ZS-DE & NA & 1.2 & NA & NA & 0.90 & NA \\
\hline
\end{tabular}

ND: Not detected; NA: Not Analyzed 
Table S2. Performance of modified filter media to inhibit growth of E. coli on the used media

\begin{tabular}{|c|c|c|c|c|c|c|c|c|c|c|}
\hline \multirow[t]{2}{*}{$\begin{array}{l}\text { Filter } \\
\text { Media }\end{array}$} & \multirow[t]{2}{*}{$\begin{array}{l}\text { Volume } \\
\text { (Liter) }\end{array}$} & \multirow{2}{*}{$\begin{array}{l}\text { Average } \\
\log _{10} \\
\text { Removal }\end{array}$} & \multicolumn{4}{|c|}{$\begin{array}{c}\text { Detection of } E \text {. Coli on Layers } \\
\text { (after } 20 \mathrm{~L})\end{array}$} & \multicolumn{4}{|c|}{ Growth in broth (after $20 \mathrm{~L}$ ) } \\
\hline & & & Top & M-1 & M- 2 & Bottom & Top & M- 1 & M- 2 & Bottom \\
\hline \multirow[t]{6}{*}{ ZS-DE } & 2 & $>6$ & \multirow[t]{6}{*}{ NA } & \multirow[t]{6}{*}{ NA } & \multirow[t]{6}{*}{ NA } & \multirow[t]{6}{*}{ NA } & \multirow[t]{6}{*}{ NA } & \multirow[t]{6}{*}{ NA } & \multirow[t]{6}{*}{ NA } & \multirow[t]{6}{*}{ NA } \\
\hline & 5 & $>6$ & & & & & & & & \\
\hline & 10 & $>6$ & & & & & & & & \\
\hline & 15 & $>6$ & & & & & & & & \\
\hline & 17 & 6 & & & & & & & & \\
\hline & 20 & $<6$ & & & & & & & & \\
\hline \multirow{6}{*}{$\begin{array}{l}10 \% \\
\text { AHC- } \\
\text { Ag- } \\
\text { AC }(60 \times \\
200)\end{array}$} & 2 & $>6$ & \multirow[t]{6}{*}{$\mathrm{A}$} & \multirow[t]{6}{*}{$\mathrm{A}$} & \multirow[t]{6}{*}{$\mathrm{A}$} & \multirow[t]{6}{*}{$\mathrm{A}$} & \multirow[t]{6}{*}{$\mathrm{A}$} & \multirow[t]{6}{*}{$\mathrm{A}$} & \multirow[t]{6}{*}{$\mathrm{A}$} & \multirow[t]{6}{*}{$\mathrm{A}$} \\
\hline & 5 & $>6$ & & & & & & & & \\
\hline & 10 & $>6$ & & & & & & & & \\
\hline & 15 & $>6$ & & & & & & & & \\
\hline & 17 & $>6$ & & & & & & & & \\
\hline & 20 & $>6$ & & & & & & & & \\
\hline \multirow{6}{*}{$\begin{array}{l}10 \% \\
\text { AHC- } \\
\text { TCC- } \\
\text { AC }(60 \times \\
200)\end{array}$} & 2 & $>6$ & \multirow[t]{6}{*}{$\mathrm{P}$} & \multirow[t]{6}{*}{$\mathrm{P}$} & \multirow[t]{6}{*}{$\mathrm{P}$} & \multirow[t]{6}{*}{$\mathrm{P}$} & \multirow[t]{6}{*}{$\mathrm{P}$} & \multirow[t]{6}{*}{$\mathrm{P}$} & \multirow[t]{6}{*}{$\mathrm{P}$} & $\mathrm{P}$ \\
\hline & 5 & $>6$ & & & & & & & & \\
\hline & 10 & $>6$ & & & & & & & & \\
\hline & 15 & $>6$ & & & & & & & & \\
\hline & 17 & $>6$ & & & & & & & & \\
\hline & 20 & $>6$ & & & & & & & & \\
\hline $10 \%$ & 2 & $>6$ & A & A & A & A & A & A & A & A \\
\hline AHC- & 5 & $>6$ & & & & & & & & \\
\hline DADM & 10 & $>6$ & & & & & & & & \\
\hline AC- & 15 & $>6$ & & & & & & & & \\
\hline $\mathrm{AC}(60 x$ & 17 & $>6$ & & & & & & & & \\
\hline 200) & 20 & $>6$ & & & & & & & & \\
\hline
\end{tabular}

M-1: Middle 1; M-2: Middle 2; NA: Not Analyzed; A: Absent /No growth; P: Present/ Growth 